\title{
Designing of KB (Family Planning) Service Information System in Pratama Clinic Salatiga
}

\author{
Penidas Fiodinggo Tanaem ${ }^{1}$, Agustinus Fritz Wijaya ${ }^{2}$, Fransiska Wahyuning Kurniawati ${ }^{3}$, \\ Resa Saputri ${ }^{4}$ \\ Satya Wacana Christian University, Salatiga, Indonesia \\ 1'penidas.fiodinggo@uksw.edu, ${ }^{2}$ agustinus.wijaya@uksw.edu, ${ }^{3} 682016088 @$ student.uksw.edu, \\ 4682016022@student.uksw.edu
}

Abstract - The writing of this Journal aims to explain the design of the $\mathrm{KB}$ service information system that is available at the Pratama Clinic Salatiga. As for the background of making this journal because Indonesia is one of the countries that has the largest population in the world and this happens because the number of births in Indonesia that cannot be controlled. Although the government has launched a KB that is applied by using contraceptives, it has not been able to overcome the problems that occur. The number of uncontrolled births is due to the large number of families who complain about the use of contraceptives. Expensive, difficult to obtain and uncomfortable when used is an excuse for those who do not want to use contraception so that the number of births cannot be controlled, besides that along with the development of existing KB services it is increasingly ignored because people prefer things that are practical and do not like to follow complicated programs or services such as family planning services so that it causes more and more people who are lazy to attend family planning and have an impact on increasing numbers birth. Seeing from the phenomena above, the thought is formed that service information systems are really needed in the current era of development, especially to facilitate all the work that cannot be done in a short time. So from this the special information system design was made in the field of family planning services in the Pratama Clinic in the form of a journal. In this journal, it explains about how a family planning service can be accessed easily without wasting too much time so that the public wants to participate in the family planning service. One way that can be done is to establish an information system that can be used for family planning services with a system that is easily understood and accessed by the general public. In this research is designing a KB service information system that can meet the needs of the community and can simplify the existing service process by using services that can be directly carried out by users who want to get $\mathrm{KB}$ services using prototyping model.

Keywords: Birth Control, Population Growth, Prototyping Method, Service Information System, Clinic.

\section{INTRODUCTION}

Family planning is one of the most basic and primary preventive health services for women, although it is not always recognized as such. Improvement and expansion of family planning services is actually one of the efforts of the government to reduce the morbidity and mortality rate of mothers so high due to pregnancy experienced by women. Many women must make difficult contraceptive choices, not only because of limited information about the number of methods available but also because certain methods may not be acceptable in relation to national family planning policies, individual health and female sexuality or the cost of obtaining contraception. Population density occurs, of course, becoming one of the problems for the Indonesian state that needs to be considered by the government so that many efforts are chosen or programmed by the Indonesian government to reduce 
population density by carrying out a family planning program. One of them is at the Pratama Clinic which also provides services for family planning for the Salatiga City community. But there are still some Salatiga City residents who are not aware of the existence of family planning services at the Pratama Clinic because of the lack of information dissemination and socialization as well as the lack of curiosity about family planning services from their own users. Therefore, the author tries to design a KB service information system that can meet the needs of the community and can simplify the existing service process by using services that can be directly carried out by users who want to get KB services. This research has a research question that is how the design of the $\mathrm{KB}$ service system can answer the problems that have occurred in the KB service process at the SWCU Primary clinic with the aim of making it easier for patients to use $\mathrm{KB}$ services

\section{METHOD}

Before the system, family planning services used a manual system where each patient had to fill out a form first and come to the clinic. Whereas with the system, patients do not need to come to the clinic, but by using the system online. The difference in the design of the previous information system at the Pratama Clinic in Salatiga City and the design of the current information system is in the method section where a similar design was carried out previously, namely using the interview method and questionnaire to the part or related parties. The interviews were conducted in the form of direct question and answer with parts or parties from the Pratama Clinic in Salatiga City. And the questionnaire was aimed at a number of patients at the Pratama Clinic in Salatiga City. While the design method used today is to conduct interviews, observation and analysis of parts or parties concerned to obtain information that will be used in making system design with a prototype method so that it is easier in making information systems design or design in $\mathrm{KB}$ services, prototyping method stages that are in it namely:

- Analysis

At this stage the user needs analysis is done through interviews and observations.

\section{- System Planning}

At this stage the system or application design will be made according to user requirements that have been obtained.

- Prototyping Evaluation

At this stage there will be a demo of the prototype model that has been developed by the developer.

\section{RESULTS AND DISCUSSION}

The design uses the prototype method through several stages in it starting from the stages of user needs analysis, system design to evaluate the results of the prototype. Questionnaires are used to obtain quantitative data to analyze how the process has occurred so far in the clinic. While observation is used to see the business process of family planning services. Based on the results of the questionnaire and observation, a KB service system will be designed using a prototyping model. The analysis phase is carried out with direct interviews together with relevant sections.In this study, the results of the analysis found that the Pratama Clinic in Salatiga City did not yet have an application regarding family planning services to facilitate the processes contained therein. The next stage is system design, The design is done using software that can describe the process flow or functionality that must be possessed by the application, user functionality is explained in the form of a usecase diagram, database process flow is described using class diagrams and Entity Relationship Diagrams (ERD) diagrams. The final stage in application design is the evaluation of prototype results, at this stage the developer explained the results of the prototype that had been made to the user, if there is a mistake of the prototype model that has been made, the developer will make improvements according to the user's wishes but if the user concerned agrees with the 
prototype has been made, then the development will continue. Here are the final prototype results that have been made :

\section{A. System Planning}

\section{User Information System Identification}

Users of the Pratama Clinic KB service information system are as follows:

1. Administrators as entities that have access rights manage all the master data in the system.

2. Midwives as entities involved in determining patient service schedules for obtaining family planning services at the Pratama Clinic and recording the results of examinations processed in the system.

3. Patients as web-based system user entities to register for family planning services and view midwife service schedules and family planning facilities provided at the Pratama Clinic.

\section{Usecase Diagram}

The following is the Use case Diagram. On the Usecase Diagram above there are 3 users who can use the system, namely admin, midwife, and patient.Admin can manage patient data, manage family planning services. Midwives can input family planning services. Patients can register for family planning services and view family planning services.

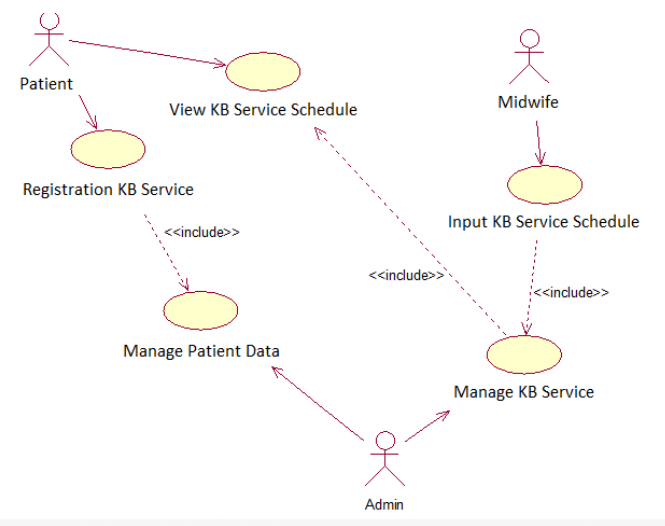

Picture 1. Use Case Diagram

\section{Activity Diagram (register for KB services)}

In this process patients can register for family planning services. At the time of registering the pasiean KB service can choose the desired type of KB. The first step the patient can click on the new KB menu then from the system displays a new $\mathrm{KB}$ form and the patient input patient data according to the provisions in the new KB form, then click Register and the system requests the storage of patient data and the database stores patient data, then the process is complete.

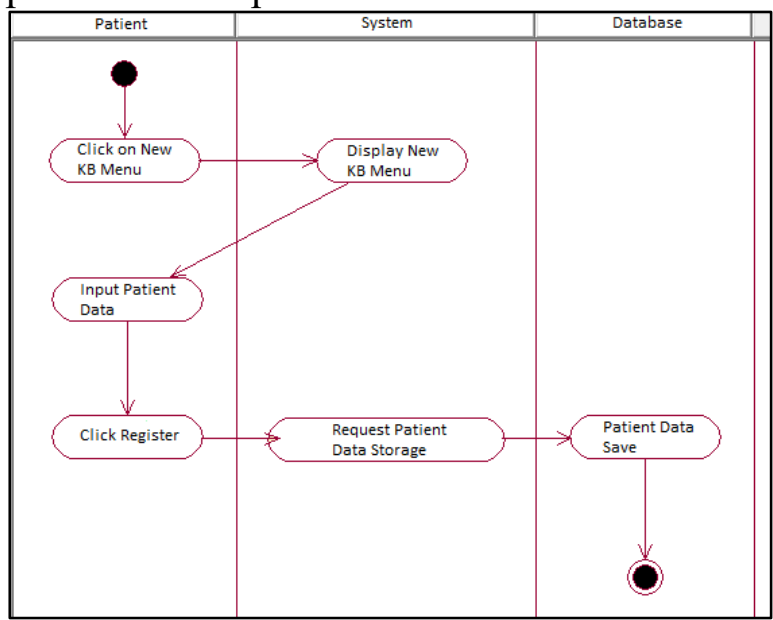

Picture 2.Activity Diagram

\section{Class Diagram}

Every process that is in the Pratama clinic has its own database. And each table has a relationship with one another. For the midwife table, it relates to the table entering the KB service schedule. For the patient table related to the table to register for family planning services and the table looks at the service schedule. And for the admin table related to managing the patient data table and managing the KB service schedule table. Then for the patient table related to the midwife table and admin table.

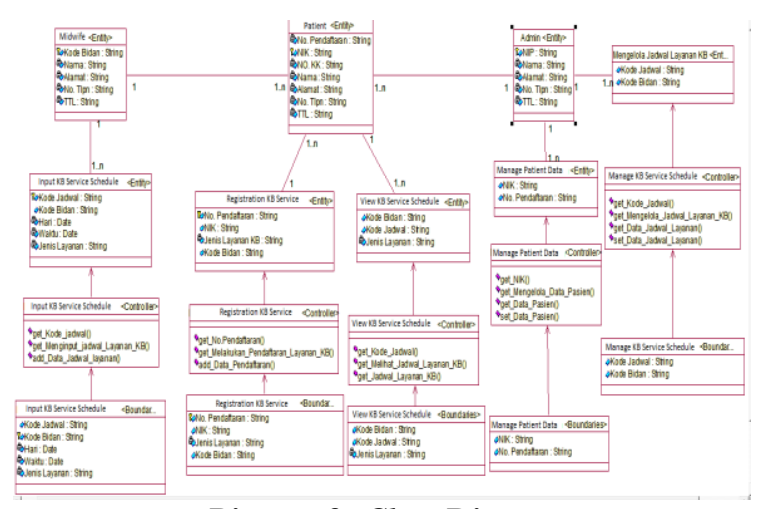

Picture 3. Class Diagram 


\section{Entity Relationship Diagram (ERD)}

The relationships that occur between $\mathrm{KB}$ service system entities can be seen in the following figure.

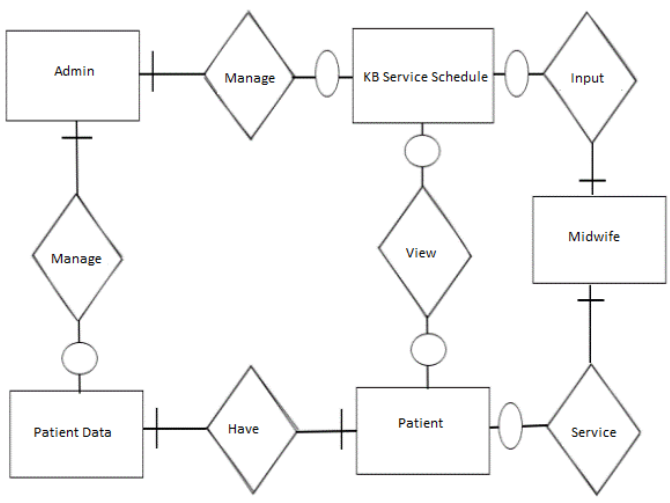

Picture 4. ERD Diagram

\section{B. User Interface (UI) Design}

\section{Login Page}

Before using this application, patients must first do the login process to be able to proceed to the desired authority page.

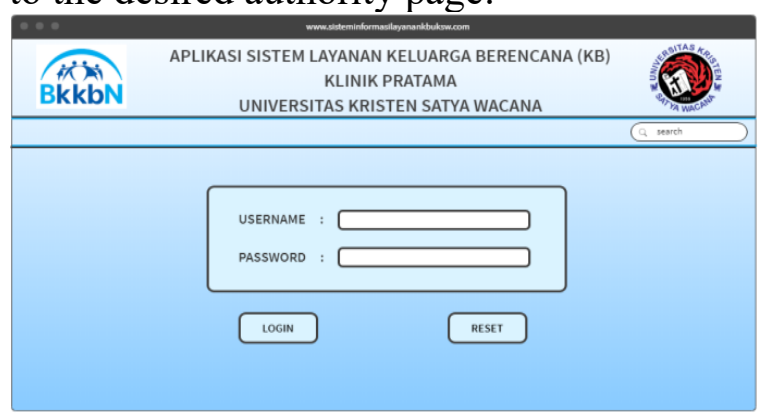

Picture 5.Login Page

\section{Main Page}

In the main view there are several menus, namely: Home, List of KB Health Facilities, New KB, KB reset, KB Supplies, Invitations, Info, Logout, and Search.

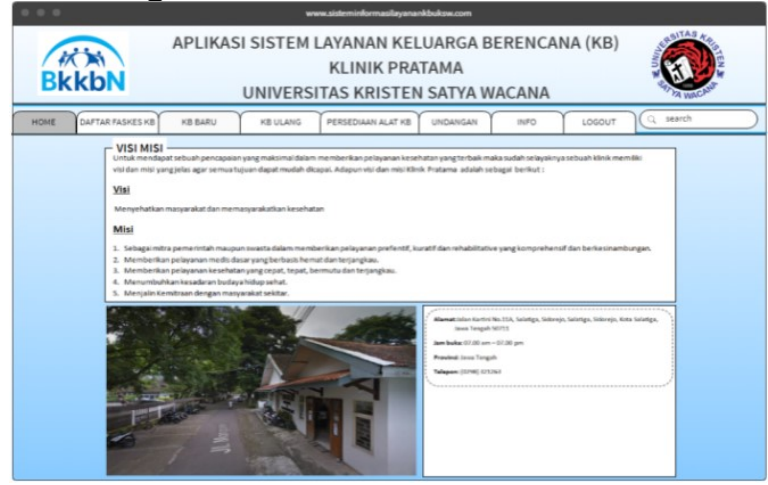

Picture 6.Main Page

\section{Midwife Schedule Menu Page}

In the display below, patients can see the schedule of midwives at the Pratama Clinic, so that it can make it easier for patients to arrange time to come to the Clinic and perform KB services.

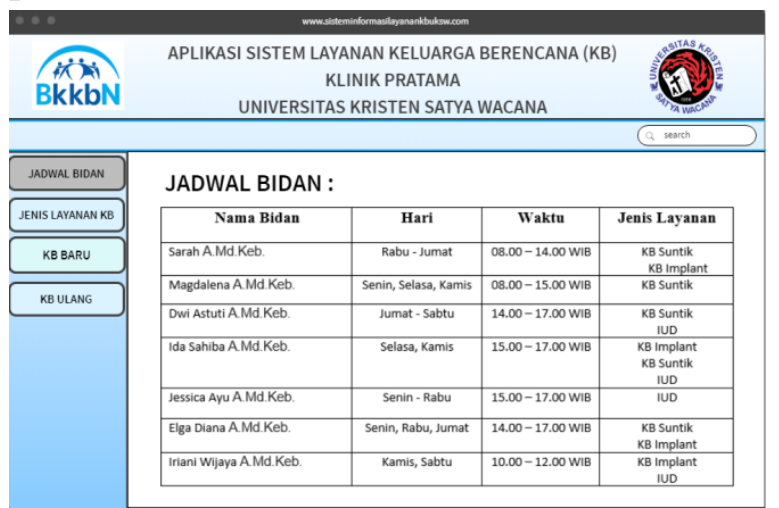

Picture 7.Midwife Schedule Menu Page

\section{KB Service Menu Page}

In the display below, patients can choose the type of family planning services they want. There are several types of family planning services that are provided by the Pratama Clinic : KB injection, IUD, dan KB Implant.

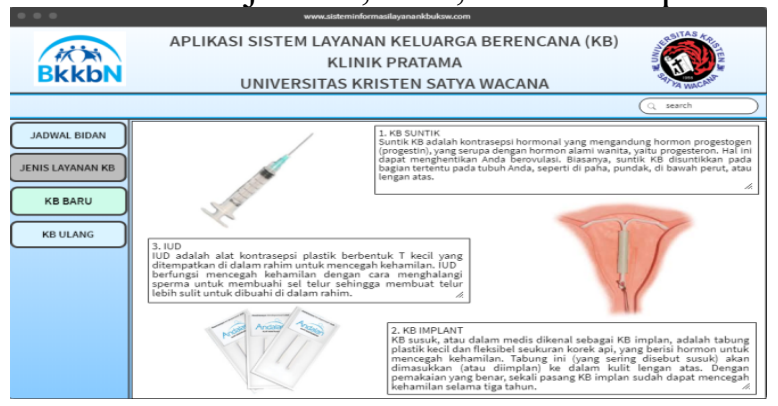

Picture 8.KB Service Menu Page

\section{New KB Menu Page}

In this process the patient registers for family planning services by filling out the form in accordance with existing provisions. 


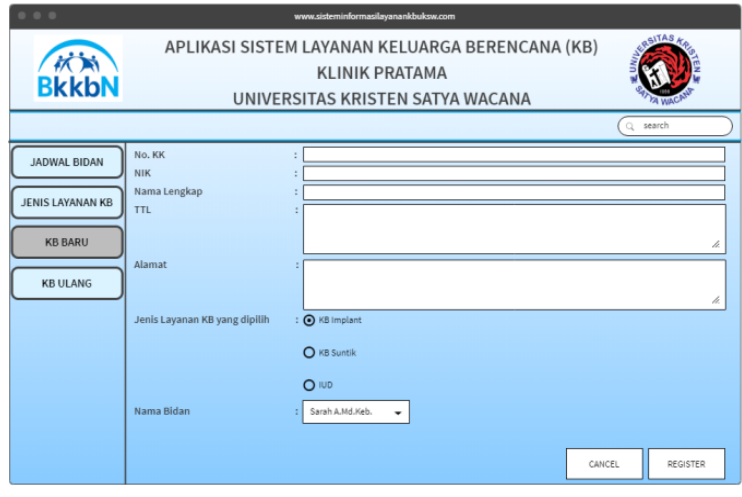

Picture 9. New KB Menu Page

After registering for $\mathrm{KB}$ services, the patient can schedule the desired midwife.

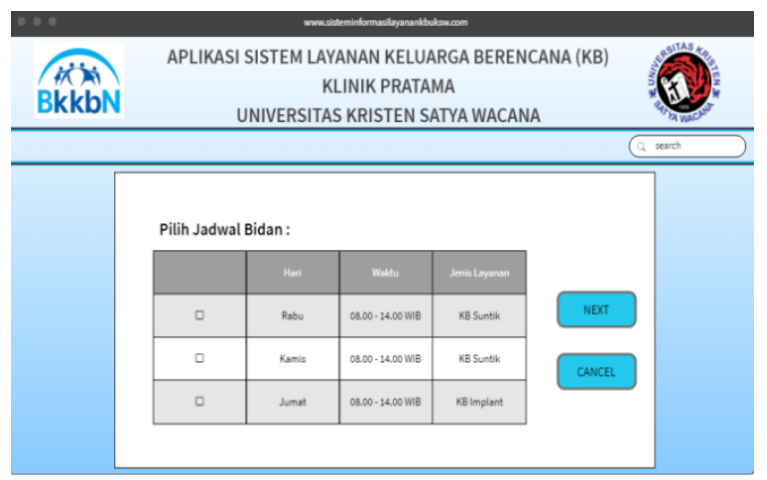

Picture 10. Display select Midwife Schedule

After completing the KB service registration form, patients can see a KB service card.

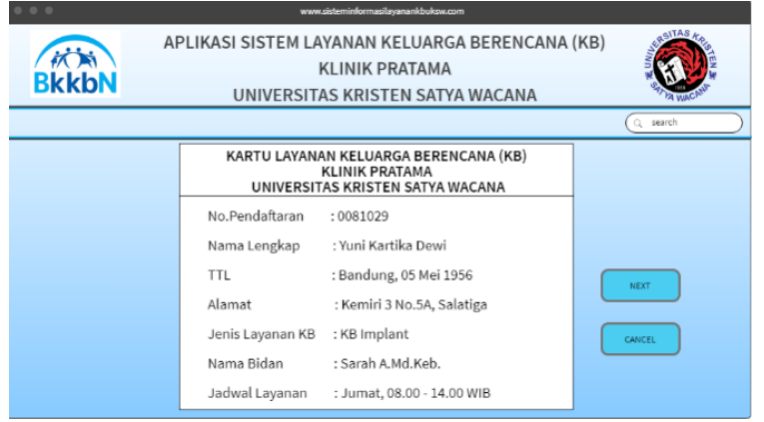

Picture 11. Service Card Display

And then the patient will get a queue number.

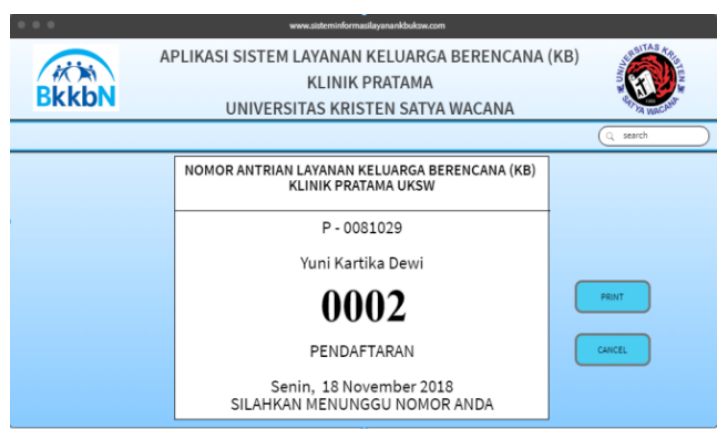

Picture 12. Display Queue Numbers

\section{CONCLUSION}

From the results of designing the system that has been made by the developer using prototyping model, finally the prototype which has been made can be well received by the user and can be drawn several conclusions, namely:

1. The KB service information system can provide convenience in terms of new patient registration, patients can easily obtain information such as seeing the schedule of family planning services available at the Pratama Clinic.

2. The KB service information system makes it easy for administrators to manage patient data in the form of medical data every time they perform or undergo a KB planning examination at the Pratama Clinic and the KB service schedule is based on the midwife's schedule which can then be used to conduct a medical recap to make a medical recap report every patient.

3. The KB service information system makes it easy to store large amounts of data with faster data access. It also saves storage space, security and data integrity can be guaranteed security.

4. Facilitate the making of queue numbers (registration) and patient identity.

\section{REFERENCES}

[1] Akhmad Syukron, Noor Hasan, "WebBased out Patient Information System Design in Winong Health Center," Journal Bianglala Informatika, Vol. 3 No. $1,2015$.

[2] Heldiansyah, Rahma Indera, Aditya Pratama AO, Fajar Shadiq, "Development of Web-Based Health Sales Information Systems at PT. Alfin Fanca Prima", Positive Journal, No. 1, 2015.

[3] Riskia Rahma Wardani, Joni Devitra, "Analysis and Design of Medicine Supply Information Systems in Payo Health Center Selincah Jambi", Journal of Information Systems Management, Vol. 2, No. 2, 2017. 
[4] Andi Taufik, Ade Christian, Taufik Asra, "Design of Health Equipment Sales Information System using the Waterfall Method", Vol. 5, No. 1, 2019.

[5] Imam Sohibbulbet, Dini Destiani Siti Fatimah, "Designing an Expert System on Android-Based Adolescent Health Problems", Journal of Algorithms, 2017.

[6] Andika Wendi Febrian, Kusrini, M. Rudyanto Arief, "Web-Based Academic Information System Designing the Academy of Health Sapta Bakti Bengkulu", Scientific Journals Data Management and Information Technology, Vol. 17, No. 2, 2016.

[7] Herupurwanto, Sopiyandalis, "WebBased Web-Based Health Care Service Information System (PKPR) in Puskesmas", jurnal.umj.ac.id/index.php/semnastek, 2017.

[8] Reza Andita, Paramiditanurul, Panji Rachmatullah, Satria Akbar, Shinta Permata, Siti Mulyaningsih, "Analysis and Design of Information Systemsdrug Services at Generic Pharmacy", Journal of Education and Research Informatics, Vol. 2, No. 1, 2016.
Hospital", Informatics Engineering eJournal, Vol. 6, No. 1, 2015.

[12] Renny Afriany N., Benni Purnama, "Analysis and Design of Medical Record Information System in TK Hospital IV Dr. Bratanata Jambi”, Journal of Information Systems Management, 2016.

[13] Yuni Sugiarti, Nur Yasin, Nur Fitriani, "Analysis and Design of Hospital Information System", Journal of Information Systems, 2015.

[14] Intan Risan Sari, Fajar Nugraha, "Listing Information System And Health Reporting Maternal and Child Health Programs in Health Services Kudus District", Simetris Journal, Vol. 7 No. 1, 2016.

[15] Rudolf Sinaga, Nurhadi, "Analysis and Design of Record Information Systemmedical in Akper Kesdam II / Sriwijaya Garuda Clinic White", Journal of Information Systems Management, 2016.
[9] Ivan Muhammad Hanif, Lenifitriani, "Software Design Record Information System Medical Based on Client-Server Study Cipanas Clinic Case", Journal of Algorithms, 2016.

[10] Yogi Purwasandina, Erwin Gunadhi, Dini Destiani, "Data Management Information System Designreferral Patients For Garut Development Puskesmas", Journal of Algorithms, 2015.

[11] Mohamad Topan, Hans F. Wowor, Xaverius B. N Najoan, "Management Information System Design Web Based 